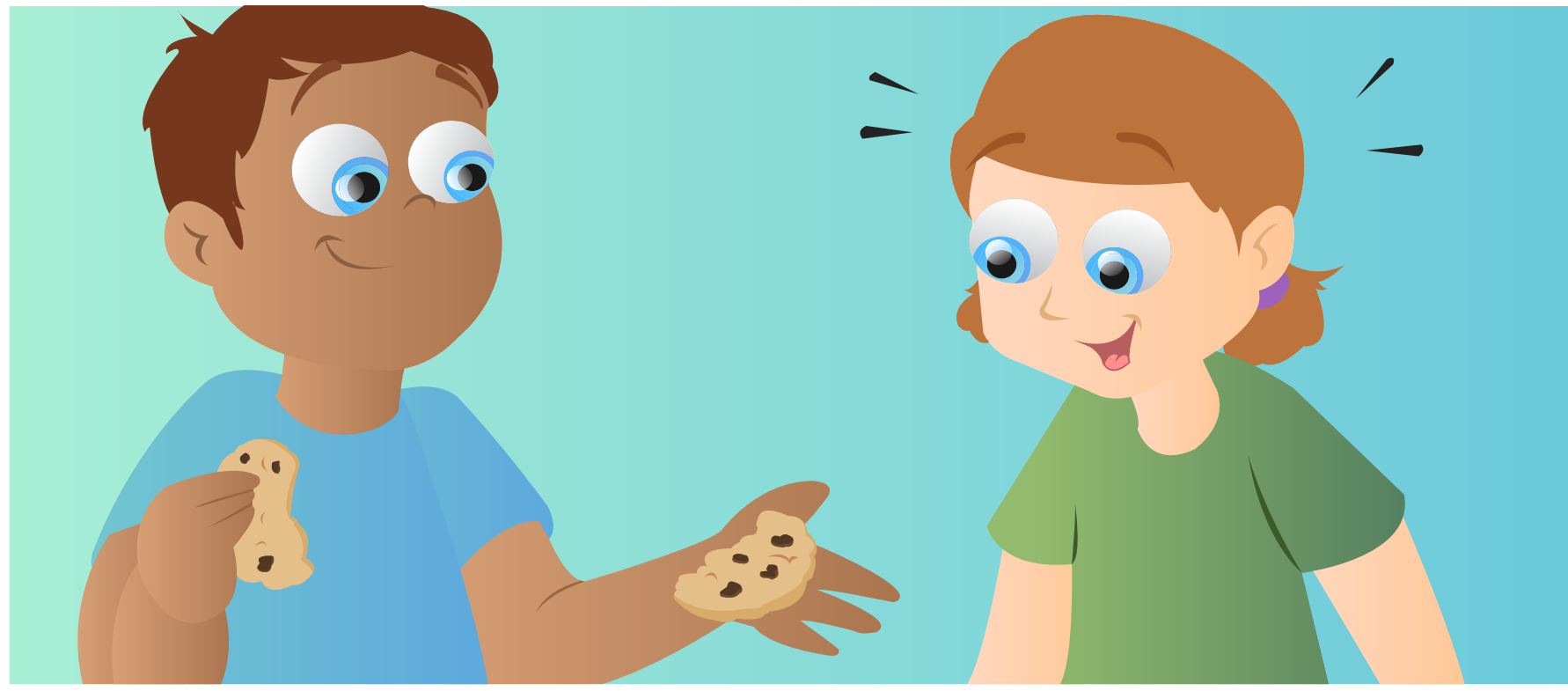

\title{
WHY ARE WE NOT MORE SELFISH? WHAT THE STUDY OF BRAIN AND BEHAVIOR CAN TELL US
}

\section{Mirre Stallen $^{1 *}$, Nastasia Griffioen ${ }^{2,3}$ and Alan Gerard Sanfey ${ }^{2,3}$}

${ }^{1}$ Department of Social and Organizational Psychology, Leiden University, Leiden, Netherlands, ${ }^{2}$ Donders Institute for Brain, Cognition and Behaviour, Radboud University Nijmegen, Nijmegen, Netherlands, ${ }^{3}$ Behavioural Science Institute, Radboud University Nijmegen, Nijmegen, Netherlands

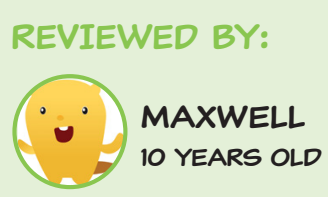

People often show a tendency toward cooperation, even though it often is a costly decision. Why this occurs is a question that has long been a topic of fascination for researchers from many different fields. Societies often do better when their citizens cooperate with each other, and so an answer to this question not only helps us to understand ourselves, but also creates opportunities for improving our society. In this article, we discuss behavioral and brain imaging research that suggests there may be several different motivations as to why we tend to cooperate instead of behaving selfishly. A tiny hint: wanting to feel good, avoid punishment, and live up to others' expectations have a lot to do with it!

\section{TO BE OR NOT TO BE PROSOCIAL: THAT IS THE QUESTION!}

Imagine you must do a team assignment in class and everyone's grade depends on the quality of the team's work. Of course, everyone expects the rest of the team to do their fair share, so that you all receive a good grade. However, what 


\section{PROSOCIAL}

Behaving in a prosocial way means that one does something for someone else. Examples of prosocial behaviors are being friendly, helping others, being cooperative, and showing trust in others.

\section{BRAIN IMAGING}

Scientists measure brain activity by using brain imaging scanners (called MRI machines). These scanners allow people to lie down in them and at the same time watch a computer screen. This way scientists can measure brain activity while people make real decisions, such as in the Public Goods Game. if you decide to do nothing and let the others do all the work? You will probably still get a good grade, assuming the others do not make the same decision, and this way you get to do something more fun with your time instead of working!

Fortunately, most of us do not behave like this. People generally are pretty cooperative, or as scientists often call it, prosocial. However, an interesting question for scientists is: Why are we not more selfish, especially when we can get away with it? Why do we often help others and invest energy in tasks, when instead we could do nothing and let others do all the work? Finding an answer to this question is important, because the success of our society depends a great deal on citizens' decisions to be prosocial instead of selfish. For instance, think about separating trash into different bins: it is important that we do this in order to make recycling possible, but the sorting does take some effort for us. Also, buying a train ticket instead of sneaking on the train for free is another example of prosociality. When everyone buys a ticket, society ends up with more money, which can then be used to keep the trains safe and affordable for everyone.

A better understanding of why people behave prosocially is not only of interest to scientists who study people's behavior, but is also important to law makers who can then try to increase prosocial behavior. In this article, we will tell you about some important things we have come to understand about prosociality and selfishness. We will discuss the results of experiments in which we simply observe the behavior of others, as well other experiments in which scientists use brain imaging, allowing us to see what happens inside the brain when people decide to be cooperative (or not).

To measure how people make these important trade-offs between selfish and prosocial behaviors, researchers have designed experimental "games" that can be used in the lab. The advantage of this approach, in contrast to studying behavior outside of the lab-in "real-life" - is that, in the lab, researchers can control the information that people receive when making a decision and closely examine what people do in these situations.

A standard game that is used to study prosocial behavior is called the Public Goods Game [1] (see Figure 1). In this game, four players are given an equal amount of money, for instance $\$ 10$ each. Each player then decides how much of this $\$ 10$ they want to contribute to a "public pot," knowing that they keep for themselves what they do not contribute. Once everybody contributes their amount, the total amount of money in the public pot is multiplied by an amount, for instance by 1.5 , and is then equally divided between all players. Multiplying the amount of money in the pot with a number larger than 1 increases the value of the money in the public pot, which makes investment in the public pot attractive. For instance, if all four players put $\$ 10$ into the pot, then the pot amount will be $\$ 60$ after the multiplying step (four players give $\$ 10$ each, multiplied 


\section{FIGURE 1}

In the Public Goods

Game, all players start with a certain amount to play with, say $\$ 10$. Next, all players get to decide what portion of their $\$ 10$ they would like to contribute to the public pot (they can choose \$0!), and they keep the remainder for themselves. After everyone has made their contribution choice, the contents of the pot are magically multiplied by a number always larger than 1, for instance 1.5. This multiplying action drastically increases the amount of money in the public pot! Now we have a MEGA pot. The content of this MEGA pot is then shared equally by all players, regardless of whether they made a contribution or not. The share a player gets from this MEGA pot is then added to whatever the player had kept from his or her initial \$10. This way, by contributing to the public pot, everyone can end up with more than they started with.

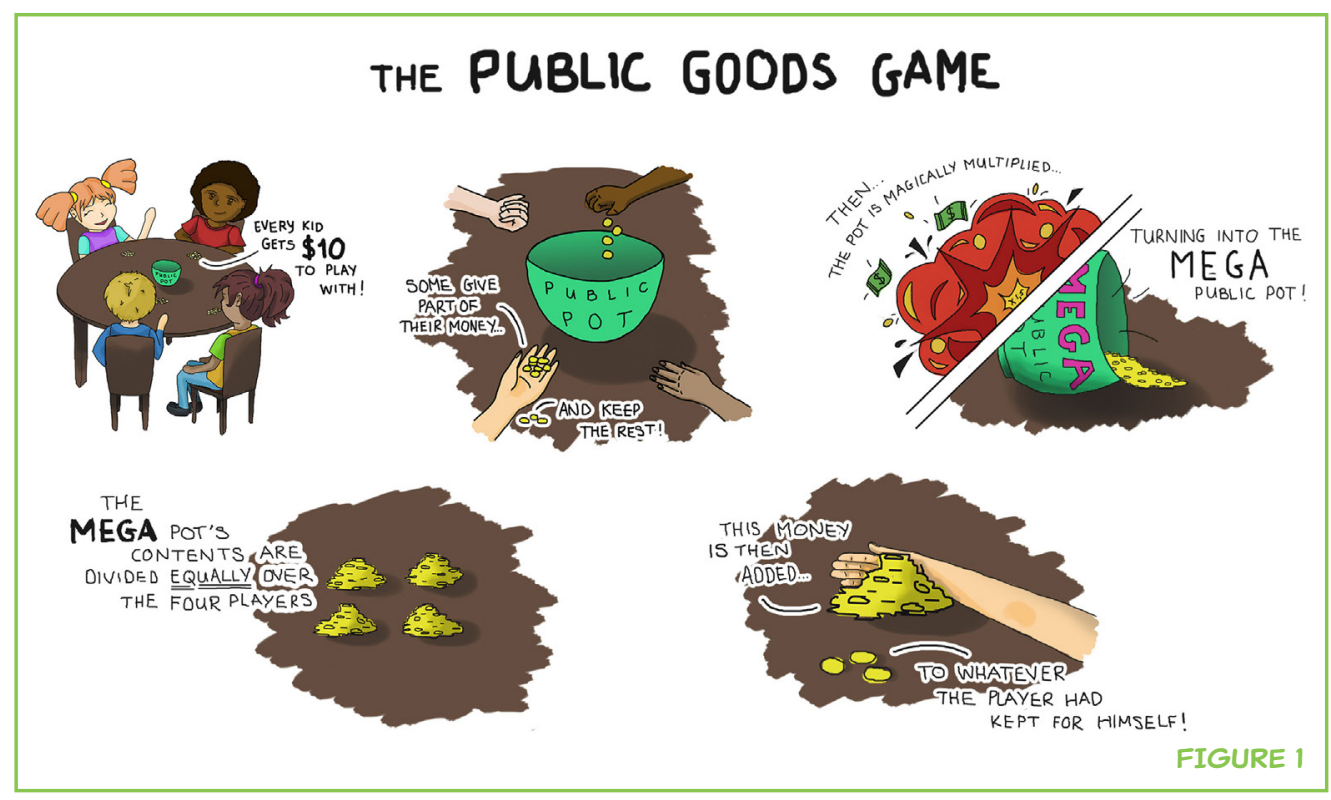

by $1.5=\$ 60)$. This means that each player will receive $\$ 15$ at the end of the round (\$60/4). If this happens, everyone has $\$ 5$ more at the end of the game than at the beginning. The magic of cooperation! However, and this is the "trick" of this game, a clever player can make even more money by not contributing anything and hoping others will. For instance, if a player contributes nothing in the above example, they keep their original $\$ 10$ for themselves and also receive an additional \$11.25 from the group pot (three players give $\$ 10$ each, multiplied by $1.5=\$ 45$, divided by four players). By behaving selfishly, this player ends up with $\$ 21.25$, which is of course $\$ 10$ more than all the others get. But what happens if everyone decides to use this selfish strategy? Then nobody gets anything! So cooperation can be profitable, but if some people try to take advantage of others, it can lead to worse outcomes.

\section{THE BRAIN'S REWARD SYSTEM IS MORE ACTIVE WHEN PEOPLE COOPERATE}

The Public Goods Game has been used in many experiments, and researchers find that people typically cooperate! That is, they give at least some of their money to the public pot, rather than keeping all the money for themselves [1]. Neuroscientists (scientists who study the brain) have found that there is a brain area that is particularly active when people behave prosocially [2]. This area is called the ventral striatum, and is located in deep within the brain (see Figure 2). Before discussing what this finding means, is it important to explain that we should be very careful when interpreting brain activity. Brain areas are usually involved in many mental processes, and not just one. So, brain activity can be interpreted reliably only when many different studies show the same result, and we are still not sure about exactly what different parts of the brain do. 


\section{FIGURE 2}

An illustration of the brain with some important brain areas highlighted. In the upper picture, you can see what the outside of the brain might look like if you were to take a peek under the skull. Shown here are the temporoparietal junction, which is an area on the surface of the brain (indicted by the solid circle). The insula is a hidden "isle" of brain tissue ("insula" being the Latin word for "island") which lies deeper into the brain (indicated by the dashed circle). In the bottom picture, you can see what the inside of the brain might look like if you were to slice someone's brain in half. Shown here are the dorsomedial prefrontal cortex (dmPFC), and the striatum.

\section{MEDIAL}

Like Lateral, the term Medial is used to explain how we look at the human body. Medial is opposite from lateral, and means "near the middle."

\section{LATERAL}

The term Lateral is used to explain from which side we look at the human body. Lateral means "from the outer side."

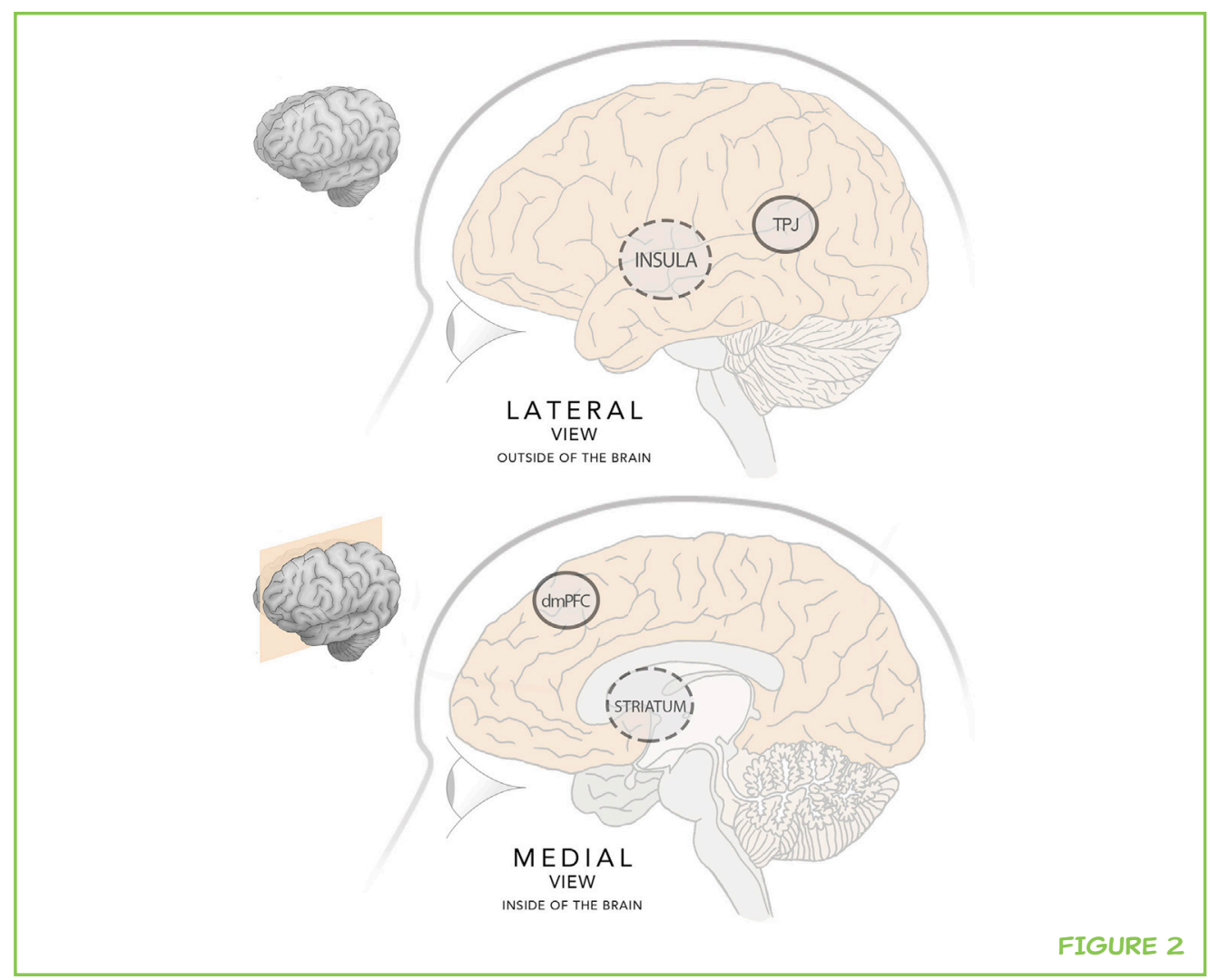

We know that the ventral striatum is part of the brain's reward system. This means that this area is active when we expect or receive rewards, such as a tasty snack or money, or when we see something that makes us feel good, such as beautiful art or a pretty face [3]. Researchers believe that the ventral striatum is an evolutionarily old area of the brain, one that was already present in our ancestors thousands of years ago.

The finding that the brain's reward system is active when people make prosocial decisions may suggest that being prosocial and cooperative with others is something we do because it makes us feel good. Acting prosocially therefore might be rewarding by itself, independent of what happens as a result of our prosocial acts. Perhaps we simply like being nice to others!

\section{PROSOCIAL OR JUST PRETENDING?}

But can it really be that simple? Could the reason we do not behave selfishly simply be that being prosocial makes us feel good? Well, the truth is a bit more complicated, and there are other explanations of why people sometimes behave prosocially. Let us go back to the Public Goods Game. Typically, when people play several rounds of the Public Goods Game, they contribute less money to the public pot in the last rounds of the game [1]. This is called the "end-of-game" strategy (see Figure 3A). One reason why people behave more selfishly only in the last rounds is that they may play the game strategically. For instance, people might choose to contribute a lot in the early rounds of 


\section{FIGURE 3}

Some different strategies shown by players in the

Public Goods Game.

A. When a player contributes most of their money in the beginning of the Public Goods Game, but then gets more selfish toward the last rounds, we call this using the "end-of-game" strategy. If a player uses this strategy, he or she probably tries to win the trust of the other players so they keep contributing to the pot. However, when the strategic player stops contributing and the others still do, this player is best off and makes the most profit. B. When a player contributes absolutely nothing to the public pot, we call this player a "free-rider," meaning that they are only in for the "gain" without any of the "pain." $\mathbf{c}$. When there is the possibility of being punished for not cooperating, we see that players tend to become more prosocial. They probably want to avoid getting punished. When there is no possibility of punishment, however, players usually decrease their contributions.
A
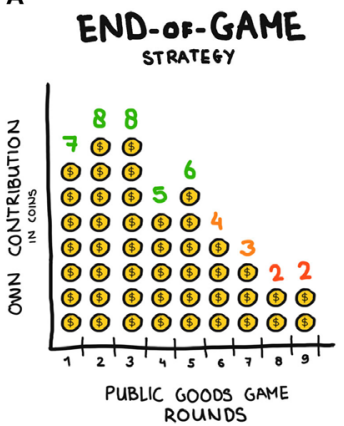

B

FREE-RIDING STRATEGY

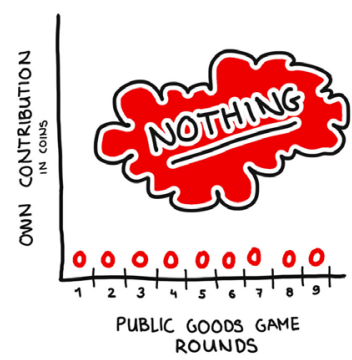

C

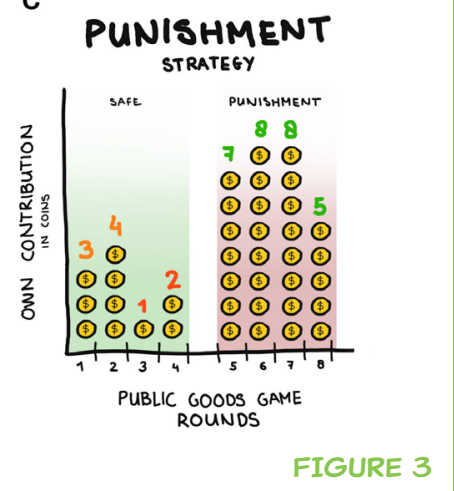

the game to show the other players that they are trustworthy. Then, in the last rounds, when the others trust them, people can take advantage of this trusting behavior of others and then invest less themselves. This allows them to make more cash. Alternatively, people might stop contributing toward the last round because they think that others might use this strategy of behaving more selfishly toward the end. By thinking about the possible motivations of others, they prevent being taken advantage of.

Strategizing and planning ahead can play a role in decision-making, and this is supported by results of brain imaging studies-here, we can use powerful magnetic fields to detect areas of activity in the brain while people are making choices in the games. These studies have found that brain areas involved in strategizing are active when people play games such as the Public Goods Game [4]. Two of these brain areas are called the dorsomedial prefrontal cortex and temporoparietal junction (see Figure 2). Interestingly, these brain areas appeared to be more active when people played with other human beings rather than with computers. We probably are better able to put ourselves in the shoes of other people, whose reasoning is more similar to that of ours, than to try to predict the choices of a computer.

\section{WE COOPERATE TO MEET THE EXPECTATIONS OF OTHERS}

In addition to feeling good and strategizing, there is a third motivation that can lead to prosocial behavior: we usually like to meet the expectations of others. In many societies, including Western ones like the United States and Europe, being prosocial is the norm. This means that others expect us to be nice and cooperative, and that we are aware of these expectations. For instance, we know that we are expected to pay for our train ticket, that we are not supposed to litter, and we know we should turn off our phones in the cinema.

Knowing that others expect us to behave in a certain way influences our behavior. This can be seen in a slightly different version of the Public Goods 


\section{SOCIAL NORM}

A norm is a rule that most people in your country or culture are aware of and that people typically follow. A social norm is a norm that tells us something about how we should behave when interacting with other people, such as being polite, friendly, helpful, and cooperative toward others.
Game: a version in which players can actually punish their fellow players. Punishment is "costly," that is-it costs some money to punish another. However, if a player decides to spend some money to punish someone else, it hurts the other a lot more (usually, every coin spent to punish decreases the income of the other by three or four coins). So, let us imagine you are playing this version of the Public Goods Game. You have invested all your money in the public pot in the first round, and at the end of the round, you are told that most other players were cooperative like you and invested money in the public pot. However, there was one person who did not contribute anything, a so-called free-rider (see Figure 3B). How do you feel about that? Would you want to punish this person?

Studies have shown that most players want to punish the non-contributor in such a situation [5], even when this punishment will hurt themselves a little. Interestingly, people behave less selfishly overall in Public Good Games in which punishment is possible, which happens even when punishment never actually occurs. This shows that people clearly know that they can be punished when they behave selfishly, and as a result they do not even try to free-ride (see Figure 3C)! They know that others expect them to be prosocial: cooperation is the social norm.

In recent years, neuroscientists have shown an increasing interest in how expectations, such as social norms, are processed in the brain. They found that the insula, a brain region involved in the experience of negative emotions like disgust or anger, is especially active when behaving in line with social norms and being cooperative (see Figure 2) [6]. But, wait? Why would a brain area that is involved in feeling bad play a role in being nice toward others? Well, it could be that this brain area, the insula, encodes the guilt that people expect they will feel if they behave selfishly. So, perhaps it is the case that, in order to avoid this guilt, people choose to behave cooperatively. That is, people might behave prosocially not only because it can make them feel good, or because it is strategic, but also because it prevents them from feeling bad later.

\section{WHAT HAVE WE LEARNT?}

To wrap up, in this article we have told you about research showing that people generally tend to cooperate, even when they might gain more from not cooperating. Neuroscience research into these questions is just beginning, but so far suggests that there are at least three motivations behind this prosocial behavior: cooperating because our brain makes us feel good when we do (reward), cooperating because we consider what others may do and plan accordingly (strategy), and cooperating because we want to avoid feeling guilty about not cooperating later on (social norms).

Why are these theories useful to have? Well, knowing what drives people to cooperate and in which situations they cooperate is very informative. 
Imagine having to work on your team assignment with a classmate who prefers to do nothing (and let us you do all the work). Not a great situation, is it? Consider how the motivations mentioned here could help you out. For instance, do you think your classmate would be more willing to do his fair share of work if punishment awaits him if he does not? Or if you tell him what you expect him to do in advance?

By building laws and rules using scientific findings and theories such as these, we can improve society and help people, such as your reluctant classmate, be a better (and perhaps even happier!) version of themselves.

\section{REFERENCES}

1. Fehr, E., and Gachter, S. 2000. Cooperation and punishments in public goods experiments. Am. Econ. Rev. 90:980-94. doi:10.1257/aer.90.4.980

2. Rilling, J. K., Gutman, D., Zeh, T., Pagnoni, G., Berns, G. S., and Kilts, C. 2002. A neural basis for social cooperation. Neuron 35:395-405. doi:10.1016/S08966273(02)00755-9

3. Bartra, O., McGuire, J. T., and Kable, J. W. 2013. The valuation system: a coordinate-based meta-analysis of BOLD fMRI experiments examining neural correlates of subjective value. Neuroimage 76:412-27. doi:10.1016/j. neuroimage.2013.02.063

4. Rilling, J. K., Sanfey, A. G., Aronson, J. A., Nystrom, L. E., and Cohen, J. D. 2004. The neural correlates of theory of mind within interpersonal interactions. Neuroimage 22:1694-703. doi:10.1016/j.neuroimage.2004.04.015

5. Fehr, E., and Gächter, S. 2002. Altruistic punishment in humans. Nature 415: 137-40. doi:10.1038/415137a

6. Chang, L. J, and Sanfey, A. G. 2013. Great expectations: neural computations underlying the use of social norms in decision-making. Soc. Cogn. Affect. Neurosci. 8:277-84. doi:10.1093/scan/nsr094

SUBMITTED: 26 April 2017; ACCEPTED: 03 August 2017; PUBLISHED ONLINE: 29 August 2017.

EDITED BY: Lesley K. Fellows, McGill University, Canada

CITATION: Stallen M, Griffioen N and Sanfey AG (2017) Why Are We Not More Selfish? What the Study of Brain and Behavior Can Tell Us. Front. Young Minds 5:47. doi:10.3389/ frym.2017.00047

CONFLICT OF INTEREST STATEMENT: The authors declare that the research was conducted in the absence of any commercial or financial relationships that could be construed as a potential conflict of interest.

COPYRIGHT (C) 2017 Stallen, Griffioen and Sanfey. This is an open-access article distributed under the terms of the Creative Commons Attribution License (CC BY). The use, distribution or reproduction in other forums is permitted, provided the original author(s) or 

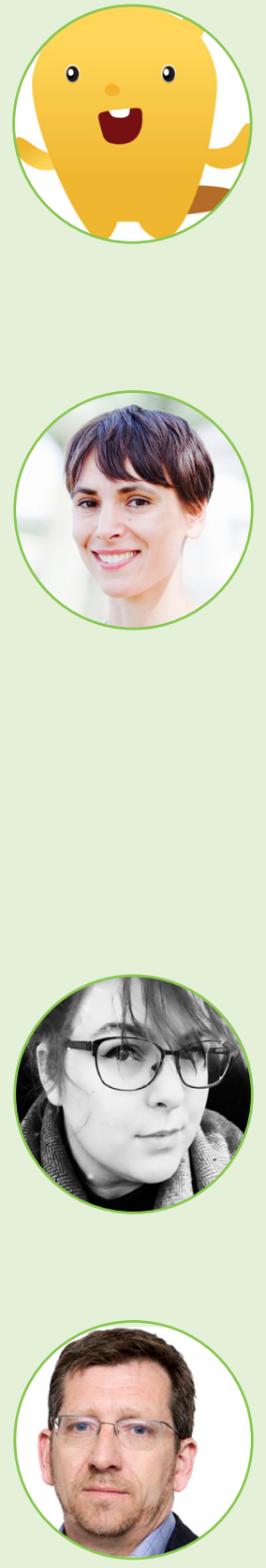

licensor are credited and that the original publication in this journal is cited, in accordance with accepted academic practice. No use, distribution or reproduction is permitted which does not comply with these terms.

\section{REVIEWED BY}

\section{MAXWELL, 10 YEARS OLD}

I am living in Beijing and I am interested in science. I like to play video games. I play piano, too. I have no brother or sister. I enjoy reading, about almost everything, not just science. I would like to know something about everything, and everything about something, which I am still looking for.

\section{AUTHORS}

\section{MIRRE STALLEN}

Mirre Stallen is an Assistant Professor at Leiden University in the Netherlands, and Senior Researcher at the University of Applied Sciences in Amsterdam, also in the Netherlands. She studies what happens in our brain when we make decisions. Central to her research is the application of scientific insights to address societally relevant issues, such as poverty and consequences arising from the growing gap between the rich and everyone else. She conducts field studies and combines methods and theories from neuroscience, psychology, and economics in order to develop effective policy interventions. She received her Ph.D. from Erasmus University Rotterdam, the Netherlands, and she was a postdoctoral scholar at the Donders Institute for Brain, Cognition and Behavior, the Netherlands, and at Stanford University, California, in the United States. *m.stallen@fsw.leidenuniv.nl

\section{NASTASIA GRIFFIOEN}

Nastasia Griffioen is a Ph.D. Candidate at the Behavioral Science Institute at Radboud University Nijmegen. She investigates the clinical applications of video games, with a special focus on depression and anxiety in adolescence. She is fond of all things applied, techy, and futuristic, and has developed an ardent fascination with the human brain ever since she got her first book about the brain at age 7 .

\section{ALAN GERARD SANFEY}

Alan Gerard Sanfey is a Principal Investigator at the Donders Institute for Brain, Cognition, and Behavior at Radboud University Nijmegen, the Netherlands. Previously he held positions as Associate Professor of Psychology at the University of Arizona, and as a postdoctoral research fellow at Princeton University. He holds a Ph.D. and Masters Degree in Cognitive Psychology from the University of Colorado, and an undergraduate honors degree in Psychology from University College Dublin, Ireland. He currently heads the Decision Neuroscience group at the Donders Institute, and his research uses a novel approach to the study of both individual and interactive decision-making by combining the methods of behavioral experiments, functional neuroimaging, and formal economic models. A further goal of his group is to use the knowledge gleaned from these studies to inform public policy debates. 